Tema: Solidificação / Lingotamento

\title{
ANÁLISE DE FALHAS NOS ROLAMENTOS DA MÁQUINA DE LINGOTAMENTO CONTÍNUO 3 DA ARCELORMITTAL TUBARÃO*
}

\section{Resumo}

Flávio Paulo Pugnal da Silva ${ }^{1}$ Amilcar Bosco Altoé ${ }^{1}$ Mauro Mantovanelli ${ }^{1}$ Gabriel Mombrini Pigatti ${ }^{2}$ Fabrício Tomé Rodrigues ${ }^{3}$

Em 2010 foram observados elevados índices de quebra de rolamentos dos segmentos da máquina de lingotamento contínuo 3 da ArcelorMittal Tubarão. As análises iniciais, realizadas pelo fabricante, sugeriram que a causa estava relacionada principalmente a falta de proteções térmicas e desvios no sistema de lubrificação que estavam deteriorando as propriedades físico-químicas da graxa. Após o restabelecimento das condições de projeto os índices de quebra mantiveram-se elevados. O objetivo deste trabalho foi avaliar as potenciais causas ligadas as falhas de lubrificação deste equipamento. Foram estudados temperatura de trabalho do equipamento, qualidade físico-química da água, vazão e velocidade da água de refrigeração dentro dos mancais e respectivos suportes. Os resultados obtidos convergiram para uma deficiência do projeto de resfriamento dos mancais e suportes. Tais deficiências geravam baixa velocidade do fluxo de resfriamento, que associada as altas temperaturas de trabalho, proporcionavam condições adequadas a precipitação de particulados contidos na água, gerando assim a obstrução gradativa dos canais de refrigeração até total colapso do sistema.

Palavras-chave: Lubrificação; Sistema de refrigeração; Lingotamento contínuo de placas.

\section{ANALISYS OF BEARINGS FAILURES AT ARCELORMITTAL TUBARÃO CONTINUOUS CASTING MACHINE \#3}

\section{Abstract}

Since 2010 the continuous casting \#3 from ArcelorMittal Tubarão has been facing high rates of segment bearing failures. The preliminary analyzes, performed by the manufacturer, suggested that the cause was mainly related to the lack of thermal protection and deviations in the lubrication system, which were deteriorating physical and chemical properties of the grease. After restore the project conditions, the failure rate remained high. The aim of this study was to evaluate the potential causes related to lubrication failures in this equipment. Were evaluated the equipment work temperature, cooling water physical and chemical properties, flow and speed within the bearings and their supports. The results converge to a deficiency of the bearings and supports cooling design. These deficiencies generated low flow rate of cooling that, associated to the high working temperatures, allowed precipitation of particulates present in the water, thereby generating a gradual obstruction of the cooling channels until complete collapse of the system.

Keywords: Lubrication; Cooling system; Slab caster.

Engenheiro de Produção, Especialista Manutenção, ArcelorMittal Tubarão, Serra, ES, Brasil. Engenheiro de Materiais, Especialista de Lingotamento, ArcelorMittal Tubarão, Serra, ES, Brasil.

Supervisor de Inspeção Mecânica do Lingotamento Contínuo, ArcelorMittal Tubarão, Serra, ES, Brasil.

* Contribuição técnica ao 45 Seminário de Aciaria - Internacional, 25 a 28 de maio de 2014, Porto Alegre, RS, Brasil. 


\section{INTRODUÇÃO}

Em 2007 a ArcelorMittal Tubarão iniciou as operações de sua terceira máquina de lingotamento contínuo de placas, com produção nominal de 3.000.000t/ano em dois veios (MLC\#3). Após dois anos de operação foram observadas ocorrências de quebra de rolamentos por deficiência de lubrificação. Em todas as ocorrências, foram observados degradação da graxa nos mancais e tubulações de alimentação, como visto na Figura 1.
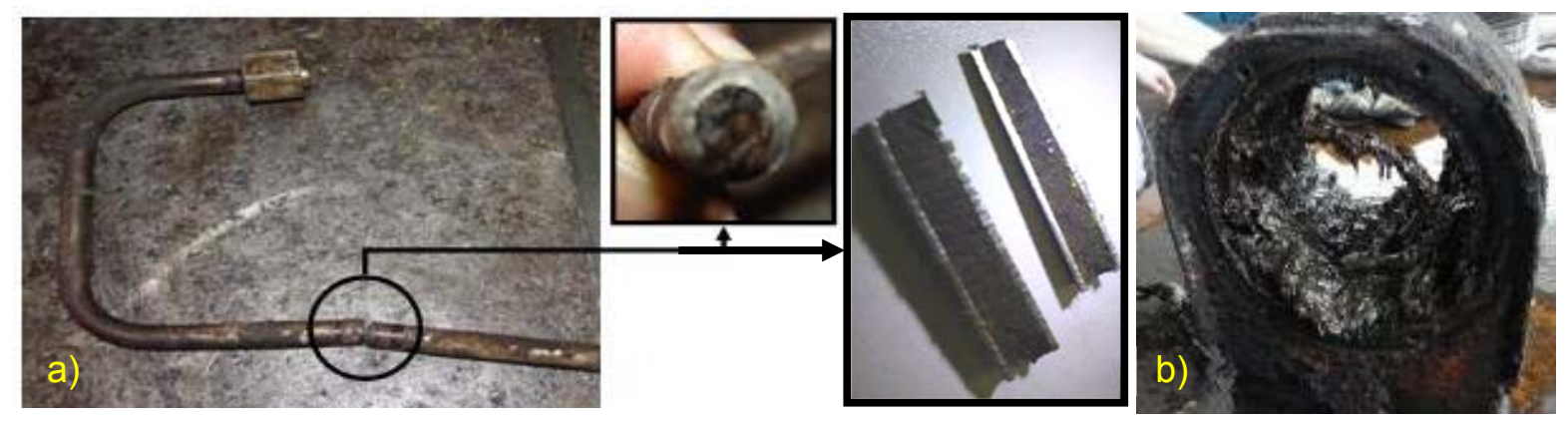

Figura 1. a) tubulação com graxa queimada em seu interior; b) mancal com graxa deteriorada.

As primeiras análises indicaram que a degradação ocorria dentro das tubulações de alimentação, uma vez que a graxa encontrava-se num estado de degradação mais avançado que no interior dos mancais (Carbonização) e que proteções térmicas previstas no projeto do equipamento não haviam sido instaladas. A Figura 2 apresenta a condição requerida pelo projeto.
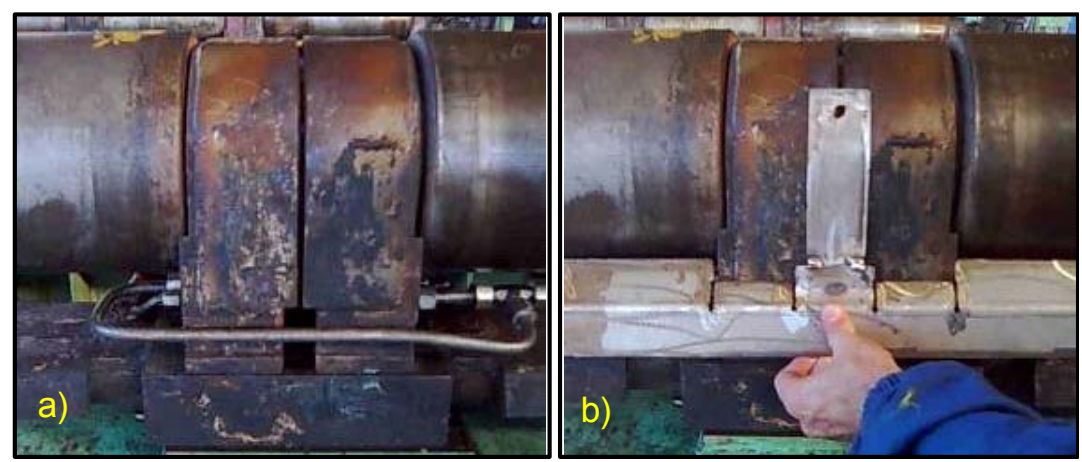

Figura 2. a) Tubulações expostas; b) Proteção térmica de projeto.

Com a propagação destas falhas somada a limitada capacidade de reparo de segmentos, houve a necessidade de paralisação de um dos veios de lingotamento para recuperação dos segmentos, reduzindo a produtividade da planta.

O fabricante do equipamento avaliou as análises realizadas pela equipe de manutenção de Tubarão e os relatórios de consultorias realizadas por empresas especializadas em lingotamento contínuo, definido plano de ação executado no decorrer do primeiro semestre de 2010, contemplando os itens abaixo:

- instalação das chapas de proteção térmica;

- substituição das vedações nacionalizadas pelas originais;

- elevação da pressão de trabalho do sistema de lubrificação;

- mudança do tipo de graxa;

- modificação das rotas das tubulações de graxa;

* Contribuição técnica ao 450 Seminário de Aciaria - Internacional, 25 a 28 de maio de 2014, Porto Alegre, RS, Brasil. 


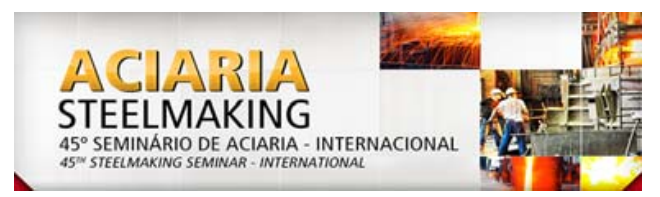

Mesmo com toda esta intervenção os resultados alcançados não apresentaram melhorias significativas no que se refere a falhas dos rolamentos por obstrução do sistema de graxa.

Com base nesta constatação, as equipes de confiabilidade, engenharia e manutenção da AM Tubarão reiniciaram as análises do problema.

O projeto deste equipamento contempla em sua arquitetura a utilização de common bases (sub bases refrigeradas na fixação dos mancais de rolamento dos segmentos), como apresentado na Figura 3. A principal função das common bases é conduzir a água de resfriamento para os mancais.

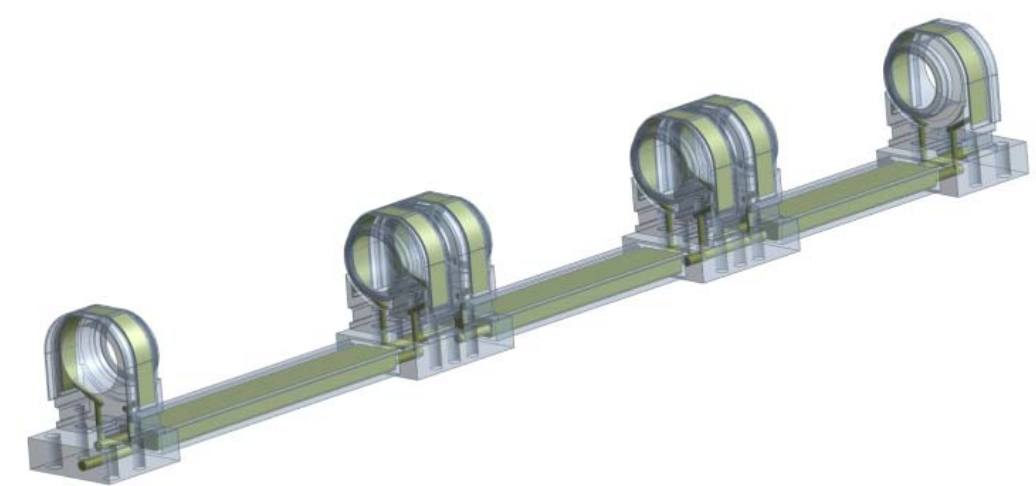

Figura 3. Esquema simplificado da montagem dos mancais na common bases.

Nesta nova etapa dos estudos o foco se voltou para a refrigeração dos mancais, cuja vazão identificada no sistema não estava atendendo o projeto, de $15 \mathrm{l} / \mathrm{min}$ por common base.

Diversas tentativas de regular as vazões do sistema foram realizadas sem sucesso, o que levantou a hipótese de obstrução no sistema. Para a constatação desta situação as common bases, de segmentos que apresentaram falhas, foram abertas e uma grande quantidade de material foi observada dentro de suas caixas. Confirmando assim a obstrução do sistema, conforme apresentado na Figura 4.

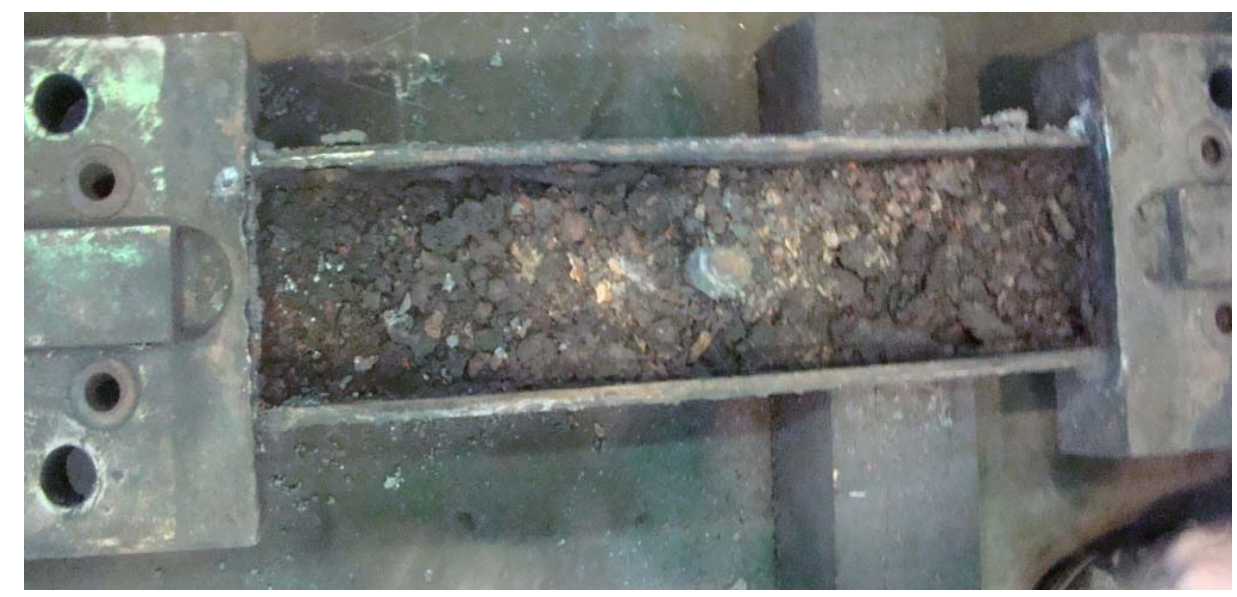

Figura 4. Acúmulo de material no interior da common base.

Neste trabalho foram estudados os mecanismos de deposição nas common bases que geram redução da eficiência resfriamento e consequentemente a queima da graxa e quebra dos rolamentos, bem como avaliar possíveis soluções.

\footnotetext{
* Contribuição técnica ao 45 Seminário de Aciaria - Internacional, 25 a 28 de maio de 2014 , Porto Alegre, RS, Brasil.
} 


\section{DESENVOLVIMENTO}

\subsection{Análise dos Depósitos Encontrados nas Common Bases}

Os depósitos encontrados nas common bases foram coletados e enviados para o laboratório de empresa parceira para realização de sua caracterização química. Foram realizadas análises químicas pelo método fluorescência de raios- $X$. Os resultados obtidos são apresentados na Tabela 1.

Tabela 1. Composição média do contaminante acumulado nas common bases

\begin{tabular}{|lc|}
\hline Componente & \% massa \\
\hline Ferro $\left(\mathrm{Fe}_{2} \mathrm{O}_{3}\right)$ & 35 \\
Silício $\left(\mathrm{SiO}_{2}\right)$ & 16 \\
Magnésio $(\mathrm{MgO})$ & 11 \\
Alumínio $\left(\mathrm{Al}_{2} \mathrm{O}_{3}\right)$ & 10 \\
Cálcio $(\mathrm{CaO})$ & 8 \\
Zinco $(\mathrm{ZnO})$ & 5 \\
Fósforo $\left(\mathrm{P}_{2} \mathrm{O}_{5}\right)$ & 3 \\
Manganês $(\mathrm{MnO})$ & 1 \\
Sódio $\left(\mathrm{Na}_{2} \mathrm{O}\right)$ & 1 \\
Enxofre $\left(\mathrm{SO}_{3}\right)$ & 1 \\
\hline \multicolumn{2}{|c|}{ Fonte: Relatório analítico NALCO } \\
\hline \multicolumn{2}{l}{}
\end{tabular}

De acordo com a análise o depósito é composto basicamente por oxido de ferro, de silício, de magnésio, de alumínio e de cálcio. A partir destes resultados não é possível afirmar que o depósito é proveniente apenas de produto de corrosão devido à presença de elementos não ferrosos.

A presença destes elementos pode estar associada ao tratamento químico aplicado à água, de forma a possibilitar trabalha-se com circuito fechado de resfriamento, ou a presença de contaminantes exógenos ao sistema.

\subsection{Caracterização da Qualidade da Água Recirculação}

Para verificação de possível influência da água utilizada para resfriamento nas ocorrências de obstrução das common bases e mancais, suas características físico químicas foram avaliadas.

Foram avaliados os resultados de qualidade química realizados diariamente pela empresa responsável pela realização do tratamento químico da água. Os parâmetros usualmente avaliados são $\mathrm{pH}$, fosfato, dureza, cloretos, ferro, zinco e sólido em suspensão. Estes valores foram comparados com os valores especificados pela própria empresa que realiza o tratamento químico do sistema. $\mathrm{Na}$ Tabela 2 são apresentados os valores de cada elemento, bem como os valores objetivados.

Tabela 2. Resultados das análises físico químicas da água de recirculação

\begin{tabular}{|lccc|}
\hline \multicolumn{1}{c}{ Componente } & Valor médio do período & Limite Superior & Limite inferior \\
\hline $\mathrm{pH}$ & 7,46 & 7,4 & 8,5 \\
Fosfato $(\mathrm{ppm})$ & 4,10 & 6 & 3,5 \\
Duzera Ca $(\mathrm{ppm})$ & 25 & 500 & - \\
Cloretos $(\mathrm{ppm})$ & 30 & 700 & 0,41 \\
Ferro $(\mathrm{ppm})$ & 0,41 & 2,00 & - \\
Zinco $(\mathrm{ppm})$ & 1,36 & 2,00 & 1 \\
Sólidos em Suspensão $(\mathrm{ppm})$ & 3,84 & 25 & - \\
\hline
\end{tabular}

Fonte: Relatório analítico NALCO

* Contribuição técnica ao 45 Seminário de Aciaria - Internacional, 25 a 28 de maio de 2014, Porto Alegre, RS, Brasil. 
Os valores encontrados não apresentaram desvios em relação à especificação, entretanto levantou-se suspeita do tamanho do particulado em suspensão na água de recirculação, o que poderia causar sua decantação em regiões de baixa velocidade de fluxo de água e consequentemente obstrução do sistema.

Foram definidos pontos para amostragem de água para realização de análises de tamanho de partículas. Os pontos escolhidos para coleta de amostras foram regiões antes do filtro com malha de $100 \mu \mathrm{m}$, após o filtro e antes das common bases e após as common bases, em segmentos que apresentavam elevada ocorrência de obstrução.

Os resultados das análises de tamanho de partícula indicaram que pelo menos $99 \%$ partículas em suspensão na água de recirculação possuem tamanhos médios inferiores a $5 \mu \mathrm{m}$ [1], como apresentado na Tabela 3.

Tabela 3. Resultados das análises de medição de tamanho de partícula na água de recirculação

\begin{tabular}{|ccc|}
\hline Ponto de amostragem & $0,5-1,0(\mu \mathrm{m})$ & $1,0-5,0(\mu \mathrm{m})$ \\
\hline Antes filtro & $97,00 \%$ & $2,80 \%$ \\
Após filtro e antes common bases & $93,40 \%$ & $5,90 \%$ \\
Após common bases & $96,60 \%$ & $3,60 \%$ \\
\hline
\end{tabular}

Fonte: Relatório analítico NALCO

Usualmente particulados com tamanhos de tal magnitude não representam problemas de decantação em sistemas similares, quando bem condicionados [1].

A associação dos resultados de análises físico químicas com a análise de tamanho de partículas induz a conclusão de que a ocorrência de deposição de particulados no interior das common bases, pode não estar associado a fatores relacionados diretamente a água de recirculação, entretanto existe a possibilidade de perda da eficácia do tratamento químico caso haja consumo além do esperado dos produtos químico utilizados ao longo do sistema, o que não pode ser avaliado pelas análises rotineiras da água de recirculação, pois a coleta de amostras neste sistema é realizada imediatamente após a dosagem dos produtos químicos.

De maneira a avaliar se existe o consumo dos produtos químicos além do previsto, reduzindo a eficácia do tratamento químicos, decidiu-se por realizar testes através da coleta água antes e após as common bases e realização de análises químicas. Os parâmetros escolhidos para esta avaliação foram o residual de dispersante e inibidor de corrosão. Os resultados são apresentados na Tabela 4.

Tabela 4. Análise do consumo dos produtos químicos ao longo do processo

\begin{tabular}{|lccc|}
\hline \multicolumn{1}{|c}{ Ponto de amostragem } & $\begin{array}{c}\text { Dispersante } \\
\text { Inerte }(\mathrm{ppm})\end{array}$ & $\begin{array}{c}\text { Dispersante Ativo } \\
(\mathrm{ppm})\end{array}$ & $\begin{array}{c}\text { Inibidor de corrosão } \\
(\mathrm{ppm})\end{array}$ \\
\hline Antes common bases & 32,9 & 23,3 & 4,2 \\
Após common bases & 32,3 & 28,0 & 4,7 \\
\hline
\end{tabular}

Fonte: Relatório analítico NALCO

Os resultados apresentados na Tabela 4 indicam que produtos químicos dosados para o condicionamento da água de recirculação se mantém em valores adequados ao longo do sistema de resfriamento. Uma outra medida para avaliar a eficácia dos produtos químicos dosados foi a realização da avaliação das medição das taxas de corrosão após as common bases. Os resultados considerados adequados para este indicador prevêem taxas inferiores $2,0 \mathrm{mpy}$ [2]. Os resultados encontrados nas medições realizadas apresentaram valores médios inferiores a 0,5 mpy.

* Contribuição técnica ao 450 Seminário de Aciaria - Internacional, 25 a 28 de maio de 2014, Porto Alegre, RS, Brasil. 


\subsection{Avaliação de Possíveis Fontes Externas de Partículas}

Avaliações das condições do sistema e seu posicionamento foram realizas com o objetivo de identificar possíveis fontes de partículas externas ao sistema que poderiam estar decantando nas common bases. Foram avaliadas o posicionamento das torres de resfriamento, condição dos enchimentos das torres e tubulações.

Os aspectos internos das torres e tubulações mostraram se adequados, pois não apresentavam deposições e produtos de corrosão.

A avaliação do posicionamento da torre indicou que o vento preferencial da região incide diretamente nas aberturas laterais das torres de resfriamento e que, além disto, existia um depósito de resíduos de refratários que poderiam ser carreados pelo vento para o interior das torres.

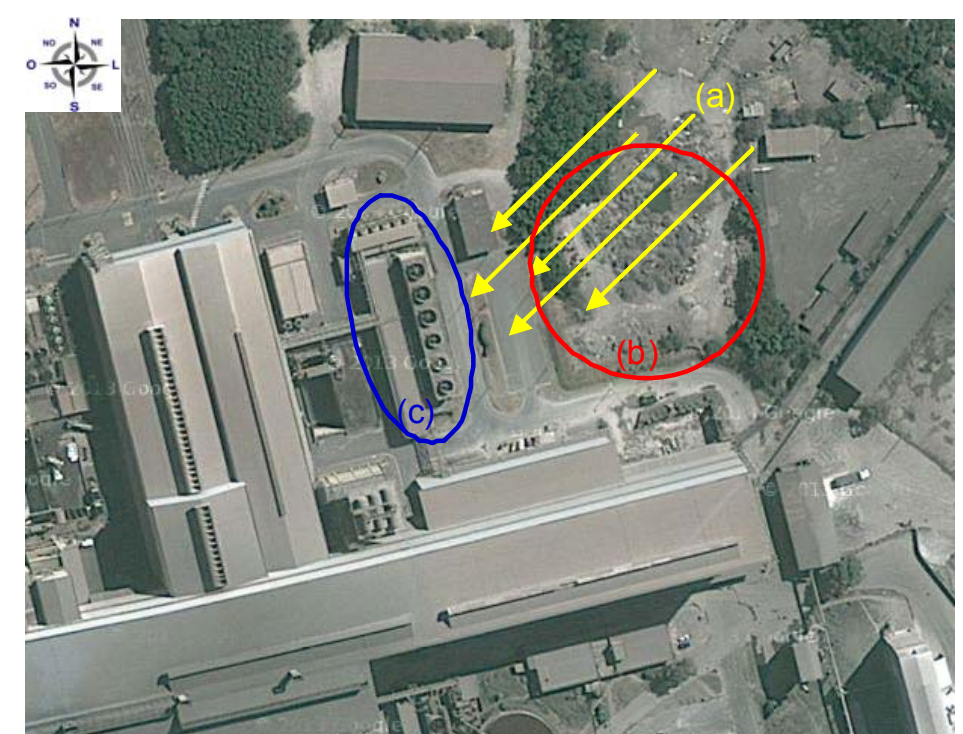

Figura 5. Vista aérea da Máquina de Lingotamento Contínuo 03. (a) direção preferencial do vento; (b) depósito de resíduos de refratário; (c) torres de resfriamento.

Mesmo havendo o carreamento de partículas de refratário para o interior da torre as medições de tamanho de partícula, apresentados na Tabela 3, indicam que estas possuem tamanhos considerados pequenos e que não representariam problemas ao sistema por si só.

\subsection{Condições de Fluxo e Condições Térmicas das Common Bases}

Para avaliar as condições térmicas e de fluxo nas common bases foram realizados estudos de simulação computacional. As informações utilizadas para o estudo foram o projeto mecânico, a vazão de água de 15 litros por minuto por common bases, temperatura de entrada da água de $28^{\circ} \mathrm{C}$ e temperatura da superfície dos mancais $110^{\circ} \mathrm{C}[3]$.

Os resultados do estudo indicaram que a condição de fluxo no interior das common bases varia em função da sua geometria. A velocidade no interior das tubulações e mancais atinge valores da ordem de $0,8 \mathrm{~m} / \mathrm{s}$, e de $0,30 \mathrm{~m} / \mathrm{s}$ nas caixas das common bases. Velocidades entre $0,8 \mathrm{~m} / \mathrm{s}$ a $1,8 \mathrm{~m} / \mathrm{s}$ são recomendadas para este tipo de sistema [4].

\footnotetext{
* Contribuição técnica ao 45 Seminário de Aciaria - Internacional, 25 a 28 de maio de 2014, Porto Alegre, RS, Brasil.
} 

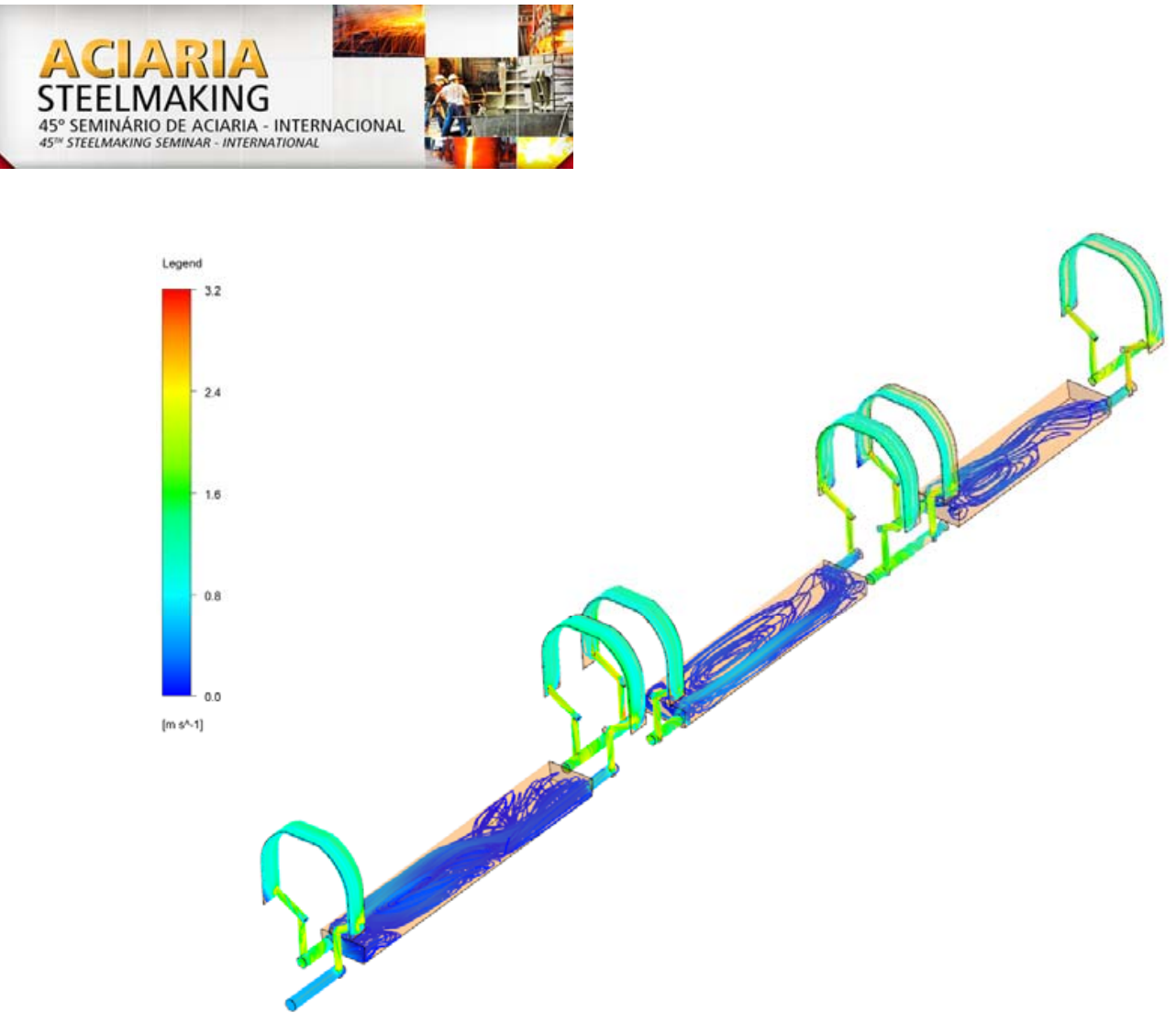

Figura 6. Simulação computacional do comportamento do fluxo da água dentro da common base.

Outra informação obtida através do estudo computacional foi o perfil térmico da água no interior das common bases em condições normais de operação da máquina de lingotamento contínuo. Detectou-se que à temperatura da água, em algumas situações, chega a valores próximos a $80^{\circ} \mathrm{C}$, conforme apresentado na Figura 7.

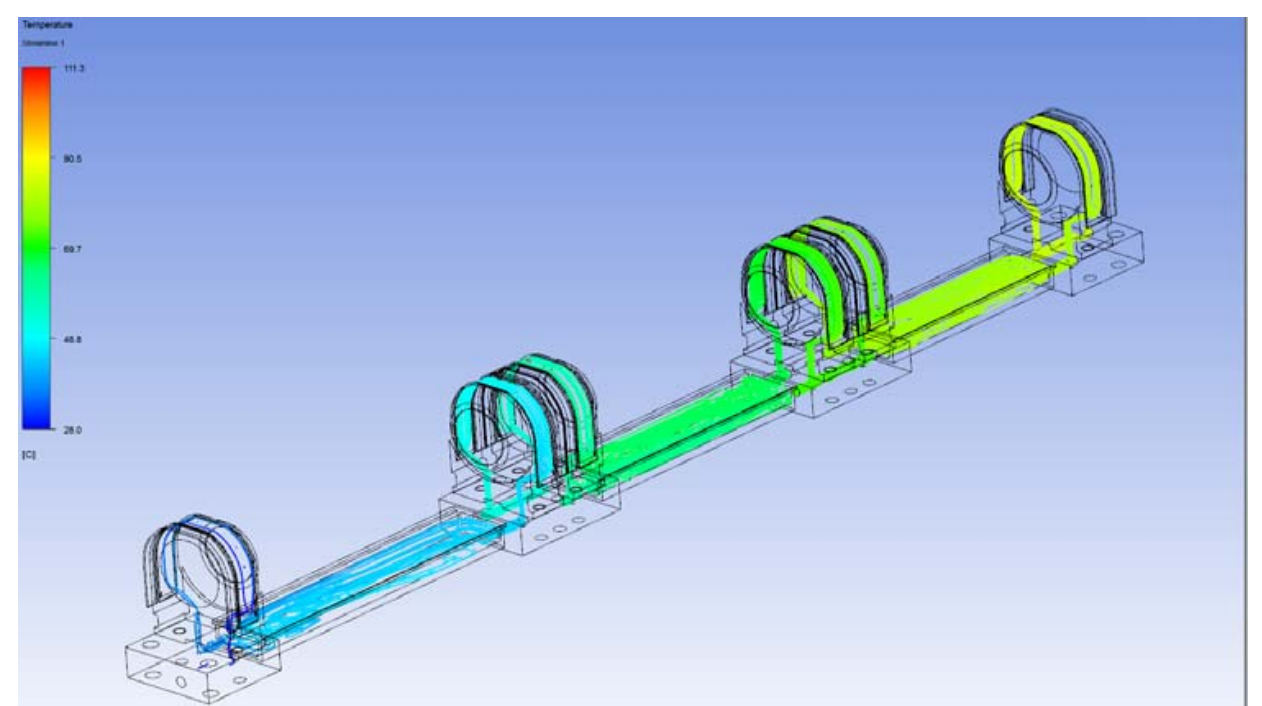

Figura 7. Simulação computacional do comportamento térmico da água dentro da common base.

Objetiva-se que águas neste tipo de sistema de resfriamento operem em temperaturas inferiores a $50^{\circ} \mathrm{C}$, pois acima deste valor inicia-se a ocorrência mais frequente da precipitação do carbonato de cálcio e magnésio solubilizados na água [5], podendo causar obstruções dos sistemas de refrigeração. As concentrações de cálcio e de magnésio presente na água é medida através de sua dureza. Os valores de dureza da água deste sistema foram apresentados na Tabela 2.

\footnotetext{
* Contribuição técnica ao $45^{\circ}$ Seminário de Aciaria - Internacional, 25 a 28 de maio de 2014, Porto Alegre, RS, Brasil.
} 


\subsection{Testes de Campo para Validação das Simulações Computacionais}

De forma a validar as informações obtidas através do modelo computacional, foram montados termopares nos canais de água dos mancais de um conjunto de common bases para que fosse medida a temperatura da água durante seu trajeto pelo sistema. $O$ desenho esquemático do posicionamento dos termopares é apresentado na Figura 8.

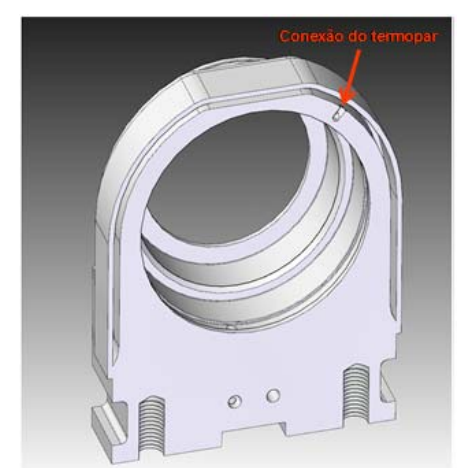

Figura 8. Desenho esquemático do posicionamento dos termopares no interior dos mancais.

Além dos termopares foi instalado um sistema de medição de vazão e válvula de controle de fluxo manual para permitir o ajuste da vazão de água no sistema durante operação. O esquema completo do sistema montado para realização destas medições é apresentado na Figura 9.

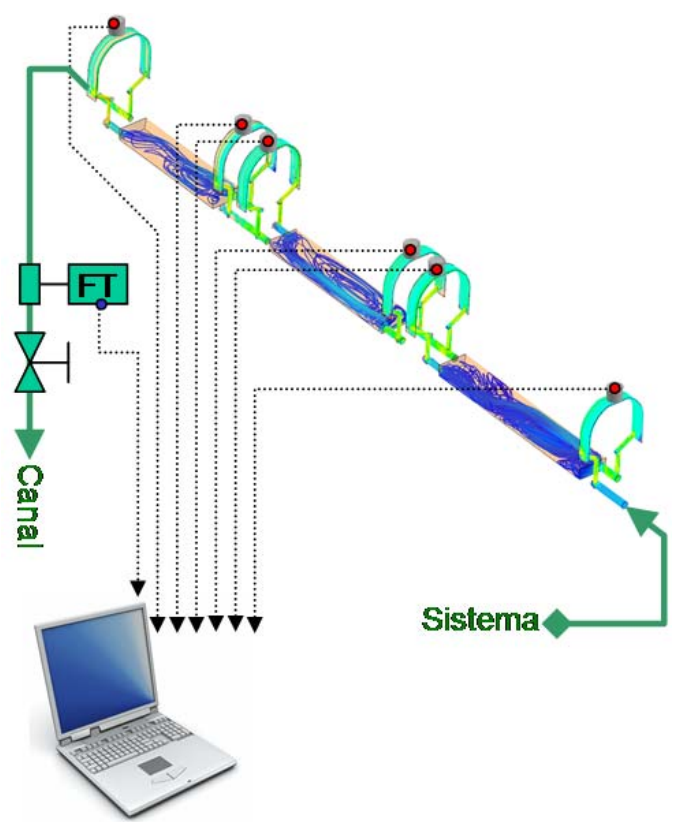

Figura 9. Esquema de instalação e registro das informações dos termopares.

A coleta de dados foi realizada durante trinta dias. Durante este período foram realizadas alterações da vazão de água do sistema para avaliar o comportamento térmico da água de saída, com objetivo de determinar qual a vazão ideal para manutenção da temperatura da água abaixo de $50^{\circ} \mathrm{C}$. Foram utilizadas vazões de 15 LPM (vazão visada de projeto) elevando-a gradativamente até 31 LPM (maior vazão alcançada no experimento) e reduzindo até 7,5 LPM (vazão mínima definida em projeto). Os resultados das medições são apresentados na Figura 10 [6].

* Contribuição técnica ao 45 Seminário de Aciaria - Internacional, 25 a 28 de maio de 2014, Porto Alegre, RS, Brasil. 


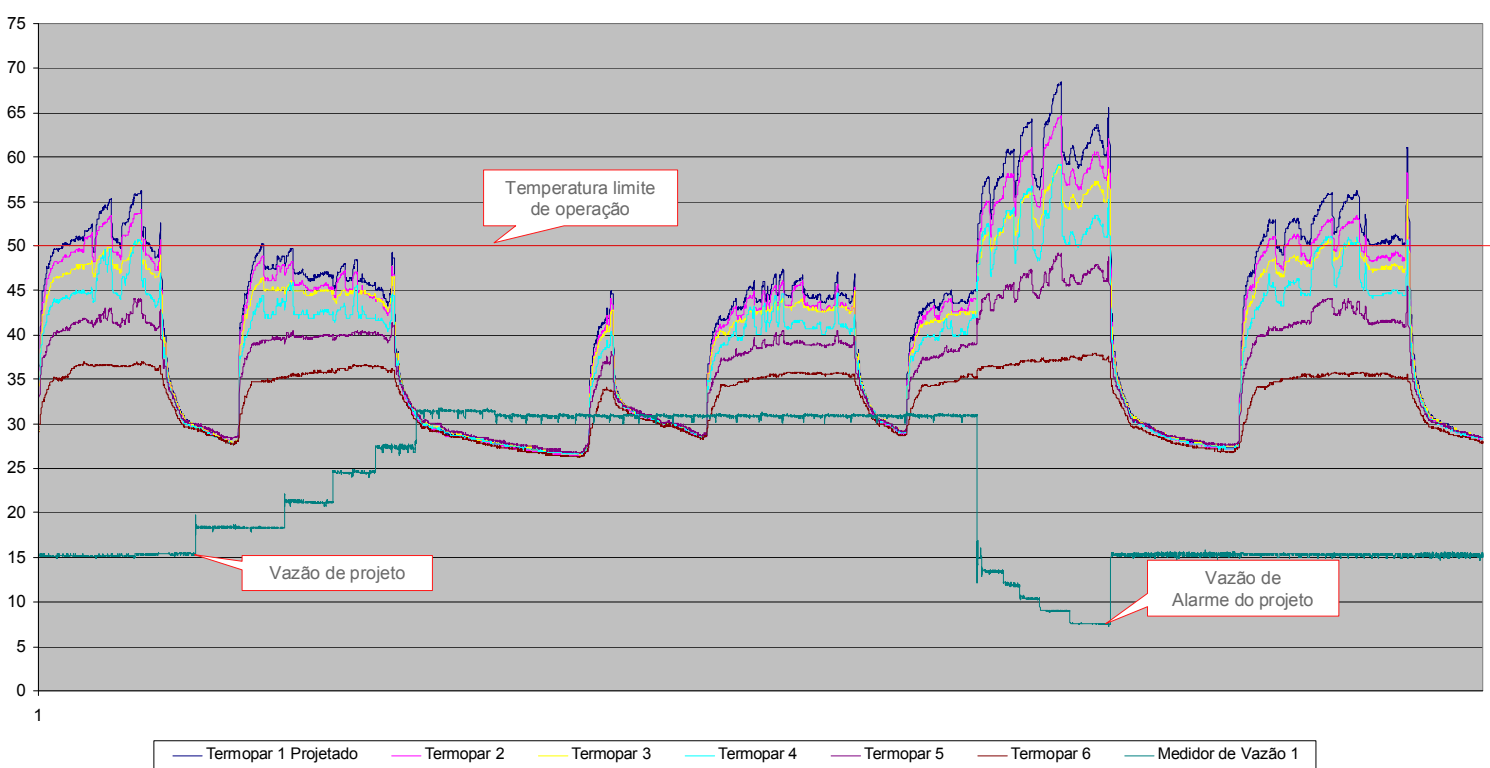

Figura 10. Resultados das medições de temperatura realizados na common base [6].

\section{DISCUSSÕES}

Os resultados físico-químicos da água do sistema de resfriamento apontaram que a qualidade da água de resfriamento não estava impactando no processo de deposição, uma vez que os fatores responsáveis por uma possível deposição/incrustação estão controlados:

- qualidade físico-química: dentro do esperado;

- particulado em suspensão: apresentando valores muito melhores que o esperado;

- presença e atividade dos produtos químicos de controle da água: dentro da normalidade.

Os estudos fluidodinâmicos apontaram baixas velocidades, ou seja, a água no interior das common bases encontra-se com velocidades de fluxo inferiores ou no limite mínimo dos valores recomendados, colaborando assim com o processo de deposição.

Com os resultados das medidas de temperatura da água na common base, observou-se que a vazão recomendada no projeto do equipamento permite que a temperatura da água atinja valores superiores a $50^{\circ} \mathrm{C}$, proporcionando a precipitação de carbonatos de cálcio e magnésio.

Somando-se as altas temperaturas, que geram a precipitação destes carbonatos, às baixas velocidades de fluxo, que além de reter, por decantação, estes carbonatos e também o particulado suspenso na água, gerou-se uma condição critica para a operação contínua deste sistema.

Neste contexto, avaliando a arquitetura do sistema (aberto com torres de resfriamento, que é sujeito a contaminação por material externo), malha do filtro do sistema $(100 \mu \mathrm{m})$ e a distribuição do tamanho das partículas presentes na água (mais de $99 \%$ das partículas com tamanho menores que $5 \mu \mathrm{m}$ ) conclui-se que o processo de deposição das common bases é tão intenso que substitui o filtro na tarefa de remoção do particulado do sistema.

Ainda na avaliação dos dados das medidas de temperatura da água, foi possível determinar que para o sistema operar com a água em temperaturas inferiores a $50^{\circ} \mathrm{C}$ é necessário que a vazão seja superior a 30LPM.

* Contribuição técnica ao 450 Seminário de Aciaria - Internacional, 25 a 28 de maio de 2014, Porto Alegre, RS, Brasil. 
A elevação da vazão de água de resfriamento deste sistema, aos níveis exigidos, demanda um total remodelamento do sistema de bombeamento e distribuição de água.

Para a estabilização do sistema até a implementação de uma solução definitiva, algumas ações foram tomadas:

- Abertura e limpeza mecânica interna das common bases e mancais;

- Monitoramento contínuo e on-line das condições de vazão de refrigeração e pressão do sistema de graxa em busca de possíveis obstruções para correção antes da falha;

- Aumento da vazão de resfriamento secundário da placa na parte reta da máquina com o objetivo de resfriamento externo dos mancais;

No gráfico da Figura 11 é possível observar a redução de falhas por Kton produzidas, onde ainda temos que considerar que no decorrer de 2010 todos os 28 segmentos da máquina de lingotamento foram retirados por manutenção devido a falhas de lubrificação, justificando o baixo valor de 2011, porém quando se observa 2012 se percebe que após um ano de operação as falhas voltam a ocorrer de forma expressiva.

Contudo após a implementação das ações voltadas ao sistema de resfriamento, se percebe, em 2013, uma redução na ordem de 50\% em relação a 2012 e mesmo em relação a 2011, onde tínhamos apenas segmentos novos, a redução foi da ordem de $28 \%$.

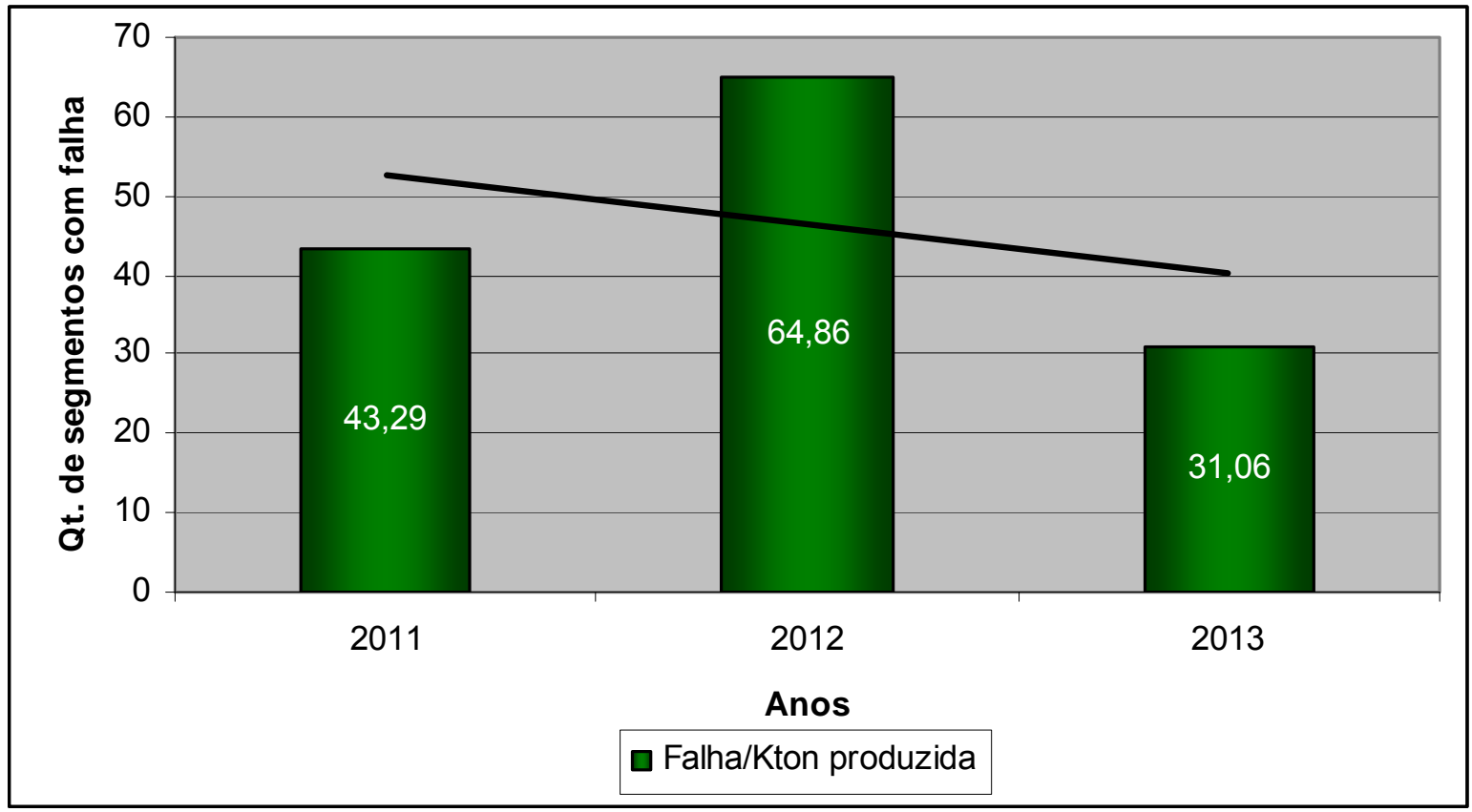

Figura 11. Relação de falhas/Kton produzidas.

\section{CONCLUSÃO}

Durante a realização deste estudo diversas ações relacionadas os sistema de lubrificação foram tomadas, pois a causa imediata da quebra dos mancais tinha relação com este sistema, porém quando se aprofundou a análise o caminho seguiu um direcionamento totalmente diferente, focando-se quase que exclusivamente no sistema de refrigeração e a geometria da common base.

* Contribuição técnica ao 450 Seminário de Aciaria - Internacional, 25 a 28 de maio de 2014, Porto Alegre, RS, Brasil. 
Este tipo de exemplo é importante do ponto de vista de validar a necessidade de utilização de metodologia de análise e não se ater ao primeiro indício encontrado, pois por de baixo de um pequeno arbusto, podemos encontrar enormes raízes.

Assim após profunda investigação, identificamos que a causa raiz por trás da quebra dos rolamentos, por obstrução do sistema de lubrificação, devido a queima da graxa em suas tubulações, se resumia a uma falha de projeto de vazão de água de refrigeração e geometria das common bases.

Ações para controlar os problemas foram tomadas, sendo possível reduzir as ocorrências de quebras em $28 \%$.

\section{REFERÊNCIAS}

1 Nalco. Relatório Preliminar: Common-Bases. Serra: Nalco; 2011.

2 Nalco. Relatório Analítico Mensal. Vitória: Nalco; 2010.

3 ArcelorMittal Tubarão. Análise Fluidodinâmica das common base - LC3. Serra: ArcelorMittal; 2010.

4 Souza EA. Avaliação de inibidores de corrosão para sistemas de resfriamento industrial operando com ciclo elevado de concentração. [dissertação de mestrado]. Rio de Janeiro: UFRJ; 2007.

5 Herro HM, Port RD. The Nalco guide to cooling water system failure analysis. Nova lorque: MacGraw-Hill; 1993.

6 Arcelormittal Tubarão. Bearings cooling system CC\#3. Serra: ArcelorMittal; 2013.

* Contribuição técnica ao 45 Seminário de Aciaria - Internacional, 25 a 28 de maio de 2014, Porto Alegre, RS, Brasil. 